\title{
MUSA CANIBAL \\ GRACE JONES E 0 DESLOCAMENTO DE RAÇA E GÊNERO \\ NA ERA DISCO (1977-1979)
}

Danilo Rabelo

Grace Jones: modelo, cantora, atriz, musa, diva, ícone gay. No contexto da revolução sexual e das culturas hibridas das grandes cidades, Grace Jones, associando-se a colaboradores como Jean-Paul Goude, Andy Warhol, Keith Haring, entre outros, produziu obra multimídia que incorpora elementos da cultura popular das ruas, dos salões de arte e da alta-costura, deslocando fronteiras culturais e ressignificando a figura arquetípica do canibal caribenho. Este artigo explora o deslocamento de raça e gênero realizado por Jones em sua trilogia de álbuns de disco music e suas performances entre 1977 e 1979 baseando-se no hibridismo cultural proposto por Édouard Glissant. [Abstract on page 246]

\section{PÓS-COLONIALISMO, HIBRIDISMO CULTURAL, RAÇA, GÊNERO, MÚSICA DISCO, GRACE JONES.}


No contexto da revolução sexual iniciada nos anos 60, a obra de Grace Jones contribuiu para a ressignificação das representações do corpo e da sexualidade da mulher, em especial da mulher afro-americana e caribenha. Deslocando as fronteiras de gênero, Grace Jones coloca em xeque os estereótipos da subalternidade e da delicadeza feminina, bem como os estereótipos da mulher afrodescendente. Este artigo analisa esses deslocamentos de fronteiras culturais e simbólicas a partir dos estudos pós-coloniais de hibridismo cultural.

Dentre os pensadores caribenhos que trabalham com a noção de hibridismo e creolidade destaca-se o martinicano Édouard Glissant, que introduz a "poética das relações", a partir do conceito de "rizoma", tomado por empréstimo de Deleuze e Guattari (1976) - e que parece melhor descrever esses traços culturais do que a noção de raiz, a qual sugere linhagem única, que toma tudo para si e elimina o restante a seu redor; rizoma é um sistema ou rede envolvente de raízes que se espalham tanto no solo como no ar, sem que nenhuma predomine permanentemente (GLISSANT, 2000: 11). Nessa perspectiva teórica as culturas americanas são caracterizadas pela mistura de diferentes tradições culturais de povos que migraram espontânea ou forçosamente para aquele arquipélago a partir do século XVI.

Celebridade controvertida por seu comportamento público impulsivo, Grace Jones, cujo nome de batismo é Grace Mendoza, nasceu em 19 de maio de 1948, em Spanish Town, Jamaica, filha de Marjorie e Robert W. Jones. Sua família possui tradição de políticos e clérigos, sendo seu tio-avô bispo, e seu pai pregador pentecostal. Em entrevis-

1 Rolling Stone. N. 350,

San Francisco: August $20^{\text {th }}, 1981$. ta à revista Rolling Stone ela relembra que "o lado paterno de minha família era muito chegado à política. O banco e a biblioteca - coisas do governo de fato. Nós éramos mantidos afastados deles porque o lado materno era muito religioso". ${ }^{1}$

Quando Grace Jones ainda era bebê, seus pais migraram para os EUA, deixando-a sob os cuidados de parentes. Ao atingir a adolescência, ela e seu irmão foram morar com os pais em Syracuse, estado de Nova York. Para justificar seu comportamento pouco convencional e impulsivo algumas fontes citam sua infância na Jamaica, de total liberdade para fazer o que bem entendesse. Entretanto, em entrevista ao jornal Los Angeles Times (18/05/1985), Jones declarou: “Desde pequena não me era permitido fazer nada... Sem televisão, sem rádio, sem cinema, nada. Nem alisar meu cabelo ou usar sapatos abertos eu podia... Mesmo quando me mudei para Syracuse para viver com meus pais, aos 13 anos, eu tinha que seguir regras rígidas."

A idealização, produzida pela mídia, da infância livre e espontânea poderia ser a repetição dos estereótipos de um Caribe selvagem, próximo à arquetípica figura de Caliban, a personagem de William Shakespeare (2006) na peça A Tempestade.

Em Syracuse, Grace Jones foi matriculada em uma escola secundária, em que praticava atletismo, o que, ela afirma, Ihe proporcionou a disciplina necessária para atingir seus objetivos (DAWIDJAN, 1978). O choque cultural, entretanto, foi inevitável: em sua rebeldia adolescente, Jones lutava contra o sistema usando cabelos afro quando isso ain- 
da não era moda e exibia os seios quando isso ainda não era aceitável. Seus vizinhos consideravam-na louca e, em sua ficha escolar, ela foi rotulada como "socialmente doente". Assim ela relembra esse período: "Eu era a única garota negra na minha escola de segundo grau. Eu tinha cabelo afro, um sotaque jamaicano, eu realmente parecia velha. Fui originalmente treinada para ser professora de línguas. Eu falo francês, espanhol, japonês, italiano e alemão. Quando me matriculei nas aulas de teatro, tudo mudou" (DISCO MUSEUM).

No caso de Grace Jones, a marginalização racial e de origem levaram a uma estratégia de sobrevivência de confronto com os valores da sociedade envolvente, criando uma identidade estigmatizada. Do mesmo modo, ela se rebelou contra o austero ambiente pentecostal de sua família e contra as expectativas de seus pais quanto a seu futuro, especialmente quando resolveu estudar teatro. Em 1978, ela mencionou essa rebeldia: de certo modo, minha família acha que eu me rebelei porque estou fazendo o tipo de trabalho que faço. Quando você é criada numa igreja e ensinada que, como mulher, só possui uma família e fica em casa até que o homem chega e te leva para sair... Eu me rebelei contra isso! Mas minha família percebe que existe outra vida lá fora, embora eles realmente se preocupem que eu me torne vulnerável (DAWIDJAN, 1978).

As expressões das culturas de origem nas sociedades receptoras provocam a discriminação e marginalização dos imigrantes organizados em comunidades etnicoculturais que tendem a ser consideradas homogêneas. Bhikhu Parekh as define assim: "As comunidades asiáticas e afro-caribenhas são étnicas por natureza, isto é, são fisicamente diferenciáveis, ligadas por laços sociais derivados de costumes, línguas e práticas intermatrimoniais compartilhadas; possuem história, memórias coletivas, origens geográficas, visões de mundo e modos de organização social próprios" (apud HALL, 2003: 67). Contudo, ele reconhece que,

ao contrário da impressão popular, grandes modificações estão ocorrendo nas comunidades étnicas e cada família tem se tornado um terreno de lutas reprimidas ou explosivas. Em cada família, marido e mulher, pais e filhos, irmãos e irmãs estão tendo que renegociar e redefinir seus padrões de relacionamento, de acordo com seus valores tradicionais e com aqueles característicos do país adotado. Cada família chega às suas próprias conclusões experimentais (idem, ibidem: 67).

Portanto, essas tradições, longe de serem imutáveis, "variam de acordo com a pessoa, ou mesmo dentro de uma mesma pessoa, e constantemente são revisadas e transformadas em respostas às experiências migratórias" (HALL, 2003: 66). São essas variações que permitem a não homogeneização dessas comunidades e seus membros. Entretanto, os interesses e motivações da ação social, sejam dos indivíduos ou das comunidades às quais pertençam, levam às negociações das diferenças culturais, negociações que não significam completa assimilação, aculturação ou integração à sociedade envolvente, mas a criação de demarcações, de fronteiras, de diferenças, bem como o hibridismo (CABRERA, 2002: 158). 
Após estudar teatro na Syracuse University durante dois anos, Jones mudou-se para Filadélfia, fazendo bicos em teatros e nightclubs durante alguns meses. Em seguida foi para Nova York a fim de seguir a carreira de modelo e atriz. Em 1973, fez um papel secundário no filme Gordon's War, dirigido por Ossie Davis, um blaxploitation, isto é, filme produzido para o público afrodescendente, trazendo atores negros para os papéis principais. Antes de continuar a narrar a trajetória de Jones ao estrelato, é necessário estabelecer o contexto sociocultural e político da época.

Durante os anos 60, a sociedade americana foi sacudida pela contracultura jovem da classe média branca, o movimento hippie. Ao lado dos protestos contra a Guerra do Vietnã, seguiam-se as lutas dos afrodescendentes pelos direitos civis. Após os assassinatos de Martin Luther King Jr. e Malcolm X, o movimento Black Power radicalizou-se com grupos paramilitares como os Black Panthers (DAUFOUY; SARTON, 1981).

Nesse mesmo período, no bojo da revolução sexual, o movimento feminista questionava as diferenças de poder e status entre homens e mulheres (HITE, 1983). E, em 1969, os homossexuais deram mais visibilidade a sua luta por reconhecimento de seus direitos com a Revolta de Stonewall, na cidade de Nova York. A década de 1960 foi encerrada com uma onda de desencanto com as promessas de uma Nova Era (Era de Aquário); com as mortes de Brian Jones, Jimi Hendrix e Janis Joplin por abuso de drogas; com o fim dos Beatles; e com a saturação da estética hippie na mídia (MUGGIATI, 1981).

Como uma ressaca dos excessos dos anos 60 , os 70 se iniciaram com a continuação dos protestos contra a guerra, mas o superávit da economia da década anterior cedeu lugar à inflação, ao desemprego, especialmente após a desvalorização do dólar e da crise do petróleo em 1973, seguida pela crise política interna dos EUA gerada pelo escândalo do caso Watergate (MUGGIATI, 1981; CHACON, 1982). A revolução sexual seguia seu curso, e as mulheres apresentavam sentimentos ambivalentes em relação a ela, conforme demonstraram no Relatório Hite:

De um modo geral é bom; principalmente há menos culpa em relação à masturbação e mais aceitação do sexo como uma parte da vida: saudável reconsideração de nossos hábitos e valores (...).

É bom que muita gente esteja falando de sexo e acho que a maioria das muIheres está se reconhecendo como seres sexuais - não como objetos passivos à espera da excitação do homem (...).

Acho que é o mínimo que se espera. Alguns dos homens com quem fui para a cama, ao me telefonar, dão seus nomes e sobrenomes pensando que eu faço com todo mundo, acho - incrível (...).

A revolução sexual me tacha de anormal se não desejo fazer com qualquer Tom, Dick ou Jane. Sou livre apenas para dizer sim (...).

Não me emociona. As pessoas estão fazendo sexo com mais frequência e com mais gente, mas o tipo de sexo da maioria ainda é doentio (...).

Conversa fiada! Os homens estão vendo mais mulheres semivestidas ou peladas, há mais "transas grátis", e há mais mulheres fingindo ter orgasmos (HITE, 1983: 339-343). 
Embora Shere Hite tenha tentado realizar um estudo profundo e rigoroso sobre a sexualidade feminina, em seus dados estatísticos não é possível identificar a etnia das mulheres que responderam aos questionários. Isso porque no início dos anos 70, o movimento feminista se apresentava como monolítico e homogêneo. As diferenças de classe e etnia, de interesses e valores só começaram a aparecer ao longo das décadas de 1970 e 1980.

Ao mesmo tempo, houve uma onda nostálgica iniciada por Hollywood com filmes como Bonnie \& Clyde (1967), The Sting (1972) e Cabaret (1973), que trouxeram para a moda os figurinos dos anos 30 (BIVAR, 1984; RABELO, 2003: 38). Essa onda nostálgica também atingiu as paradas de sucesso, com artistas pop regravando antigas composições bem-sucedidas. Se, porém, era essa a tendência dominante do gosto popular, massificada pela mídia, havia dois movimentos culturais ligados às comunidades afrodescendentes: o cinema blaxploitation e a música disco. O primeiro inovou a chamada sétima arte ao colocar atores negros nos papéis principais dos filmes e lançar excelentes trilhas sonoras com base no funk e no soul e letras contestatórias. Entretanto, esse tipo de filme foi duramente criticado por retratar os afrodescendentes como heróis que fazem justiça com as próprias mãos e, principalmente, como gigolôs, cafetões, chefes mafiosos de gangues, etc. (MILLS, 1990).

O segundo, por sua vez, era originário das discotecas francesas da década de 1940, pois durante a ocupação nazista a música ao vivo foi banida dos bares e cabarés (GOLDMAN, 1978). A música secular negra estava voltada para a dança, principalmente com a eletrificação do blues, que deu origem ao rhythm and blues e evoluiu para o soul e o funk. Nos anos 60, já havia nos EUA e na Europa clubes que tocavam discos de músicos negros, principalmente, das gravadoras Motown e Stax e, na década seguinte, da gravadora Philadelphia International Records (PIR).

Os discos de rhythm and blues eram classificados pela indústria musical como "race records" (gravações raciais) nos anos 50, mas com a adoção de vocais mais adocicados e cordas pela gravadora Motown, a chamada música negra conseguiu realizar o crossover, isto é, agradar ao público de classe média branca (DAUFOUY \& SARTON, 1981: 51-70). As produções da PIR, no início dos anos 70, aumentaram o uso de orquestra aproximando o rhythm and blues da música pop. Entretanto, essa nova música dançante ainda não tinha nome. Ainda que essas canções chegassem muitas vezes ao topo das paradas de sucesso, como "Love Train" (1972), do grupo The O'Jays, elas eram mais executadas nos bares e clubes frequentados por homossexuais. Assim, a música de dança se tornara uma música do basfond, um fenômeno underground, logo associado ao movimento do Gay Power, e passaria para a história como um fenômeno da subcultura gay. Em Nova York, além do famoso Stonewall Inn, havia também os clubes frequentados por homossexuais como Le Jardin, The Limelight, The Anvil, entre outros. Da costa leste à oeste houve uma proliferação de clubes gay nas grandes cidades norte-americanas. Portanto, desde o início, na Paris dos anos 40, e durante sua evolução nos anos 60 e 70 a discoteca era um fenômeno subversivo e multicultural (KERSHAW, 1997: 20). 
Por volta de 1974, a nova música já havia sido batizada disco e se tornaria um fenômeno mundial, em 1977, com o filme Saturday Night Fever. O crítico John Rockwell escreveu no The New York Times: "A discoteca representa uma parte vibrante da segunda metade dos anos 70, tanto a subcultura homossexual/negra/latina como as emulações dos brancos de classe média. E, apesar de todo o seu escapismo tolo, é uma das periódicas e bem-vindas incursões da cultura negra na corrente cultural branca" (apud MUGGIATI, 1981: 109).

Era esse o ambiente que Grace Jones encontrou ao chegar a Nova York. Após diversos bicos, ela conseguiu contrato com a famosa agência de modelos Wilhelmina Modeling Agency. No início dos anos 70, sua imagem agressiva e andrógina causava estranheza, pois ela já havia raspado a cabeça. A pele escura, a voz grave, o corpo esguio e tonificado eram fortes demais para o gosto norte-americano (NEWSWEEK, New York, vol. 106 , July $1^{\text {st }}, 1985$.). O expediente de raspar a cabeça fora uma decisão estudada: "Eu a prefiro desse jeito. Eu tentei muitos looks diferentes, modelando e tudo mais. Trabalhar como modelo me deu a oportunidade de usar muitos estilos diferentes, e eu escolho um que acho mais adequado a minha personalidade. Ele costuma revelar que é diferente do comum" (DAWIDJAN, 1978).

Jones já era, entretanto, frequentadora assídua dos clubes gay como o Le Jardin (MADEMOISELLE, 1982). Então partiu para Paris, onde foi capa de Essence, Elle, Vogue e Der Stern e desfilou para Yves Saint Laurent, Claude Montana, Kenzo, entre outros estilistas. Em Paris, sua imagem exótica foi associada a uma artista negra que havia conquistado a Cidade-Luz: Josephine Baker (1906-1975).

Baker era excelente dançarina e cantora negra de vaudeville dos EUA que emigrou para a França em 1925. Seu principal número no Folies Bergère consistia de uma dança em que aparecia seminua, usando apenas um saiote feito com bananas artificiais. Até sua morte, Baker foi notável dama do teatro, cinema, ativista pelos direitos civis nos EUA e amiga de grandes celebridades do século XX. Dentre seus cognomes se destacam: Vênus de Bronze, Pérola Negra e Deusa Créole.

À primeira vista, a imagem de Baker seminua com bananas era recorrente do imaginário europeu: o negro e/ou a negra hipersexualizados, lascivos, promíscuos em sua animalidade. As bananas eram recorrentes na associação do negro aos grandes primatas. Segundo o psicanalista Jolande Jacobi (1997: 300),

O homem negro é, para algumas pessoas, a imagem arquetípica da "criatura primitiva e sombria", portanto uma personificação de certos conteúdos do inconsciente. Talvez seja esta uma das razões por que o negro é, tantas vezes, rejeitado e temido pela gente branca. Nele o homem branco vê, diante de si, a sua contrapartida viva, o seu lado secreto e tenebroso (exatamente o que as pessoas tentam sempre evitar, o que elas ignoram e reprimem). Os brancos projetam no homem negro os impulsos primitivos, as forças arcaicas, os instintos incontrolados que se recusam a admitir em si próprios, de que estão inconscientes e que imputam, consequentemente, a outros. 
Quanto à mulher negra, de acordo com Gerda Lerner (1973: 163), após o final da escravidão sua exploração continuou tanto no norte quanto no sul. Para sustentá-la diante da liberdade nominal dos homens negros, um complexo de mecanismos e mitos de apoio foi criado. Um desses mitos era o da mulher negra "má". Ao assumir um nível de diferente sexualidade para todos os negros e mitificando seu maior apetite sexual, a muIher negra poderia personificar a liberdade sexual e o abandono. Criou-se o mito de que todas as mulheres negras eram ansiosas por façanhas sexuais, voluntariamente "relaxadas" em sua moral e, portanto, não mereciam a consideração e o respeito garantidos às mulheres brancas. Se, porém, esse era um mito criado nos EUA, a imagem lasciva da muIher negra também era um fetiche para o imaginário colonialista europeu.

Na década de 1920 havia uma fascinação francesa pela "nova América", sua inovação tecnológica e sua cultura popular, entendida como sinônimo de cultura negra: jazz, músicos e dançarinos negros. Josephine Baker em suas performances e Alexander Calder (1898-1976) em seus retratos de arame de Baker acrescentaram primitivismo tecnológico às noções de primitivismo associado ao corpo negro e à África e, ao mesmo tempo, evocando a vitalidade tecnológica dos EUA. (ZABEL, 2001: 299).

Do mesmo modo, os cabelos curtos e a voz variando de registros doces e femininos para o grave e gutural exibiam ambiguidade que colocava em dúvida o sexo de Baker, levando o crítico Pierre de Reginier, em 1925, a se perguntar: "é um homem ou é uma mulher?" (idem, ibidem: 314-315). Além disso, as bananas de seu saiote combinavam o fálico e o feminino num único corpo. Tanto o corpo quanto os cabelos eram definidos como uma máquina quase perfeita, uma estética da máquina associada à masculinidade. Em vez de posar como nativa submissa, essencializada e unificada ao ambiente da selva, Baker transformou-se na dona da selva (idem, ibidem: 315).

A influência de Josephine Baker sobre o trabalho de Grace Jones é considerada por Carolyn G. Anderson (1993) indireta. Entretanto, essa influência foi crucial para as imagens e performances de Jones, conforme discutido adiante. ${ }^{2}$

O início da carreira musical de Grace Jones parece estar cercado pelo acaso. Segundo a edição de julho de 1979 da revis-

2 Cf. também Benetta Jules-Rosette, Josephine Baker in Art and Life: The icon and the image. Champaing: University of Illinois Press, 2007. ta Ebony, por volta de 1974, Grace estava jantando com alguns amigos num restaurante quando ouviu a canção "Dirty Old Man" das Three Degrees; saltou então sobre a mesa e começou a cantar junto com o disco. A plateia, cativada, aplaudiu a performance inusitada, e uma modelo que ali se encontrava a apresentou a seu namorado, que era produtor de discos. A princípio, Jones assinou contrato com uma pequena gravadora francesa. Três anos depois, com a gravadora Island, do anglo-jamaicano Chris Blackwell, distribuidor dos discos de Bob Marley.

A essa altura a música e a subcultura disco já não era fenômeno underground, com cantoras como Donna Summer e Gloria Gaynor disputando na imprensa especializada o título de Rainha das Discotecas e agradando muito ao público heterossexual e, especialmente, ao público gay. Donna Summer, no final de 1975, lançou o sucesso "Love to 
love you baby", apresentando bela voz entrecortada por sussurros, gemidos e simulações de orgasmos, que se sucediam disco após disco até 1978, quando, já estabelecida como estrela internacional, decidiu abandonar a imagem de deusa sexual. A imagem da mulher negra lânguida, lasciva e hipersensual continuava recorrente.

O álbum de estreia de Jones, intitulado Portfolio (1977), foi gravado na Filadélfia com os músicos da PIR e com produção do famoso DJ Tom Moulton. O primeiro lado trazia um medley de três conhecidas canções da Broadway: "Send in the clowns", "What I did for Love" e "Tomorrow", interpretadas em estilo disco, camp e/ou kitsch. O segundo lado, porém, trazia quatro canções que se tornaram clássicos da música disco: "La vie en rose" (regravação do clássico de Edith Piaf, cantado em francês e inglês), "Sorry", "That's

3 A autoria das canções é a seguinte: "Send in the clowns", Stephen Sondheim; "What I did for Love", Marvin Hamlish \& E. Kleban; "Tomorrow", Martin Charnin \& Charles Strouse; "La vie en rose", Édith Piaf \& Louis Gugliemi; "Sorrow", Grace Jones \& Pierre Papadiamondis; "That's the trouble", Grace Jones \& Pierre Papadiamondis; "I need a man", Pierre Papadiamondis \& Paul Slade. the trouble" e "I need a man". 3

A imagem andrógina de Grace Jones agradou de imediato aos gays. Portanto, esse era o seu maior público, e logo ela recebeu o título de Rainha das Discotecas Gay. A revista Ebony questionava sua aparência ambígua: "Então ela é europeia? Africana? Sul-americana? Ela não é realmente um homem? Ela mudou de sexo?" (1979). A partir de sua experiência como modelo, Jones explicou assim seu sucesso junto aos gays: "Isso tem a ver com estilo e moda. No show business, pessoas gay basicamente têm mais bom gosto. Não há dúvida sobre isto: gays são mais sensíveis, mais conscientes da forma, mais artísticos e muito mais abertos para aceitar algo novo e com frescor" (DAWIDJAN, 1978). Porém, essa é uma generalização excessiva, que "essencializa" as identidades homoeróticas em um estereótipo. Por outro lado, Jones vinha de uma cultura extremamente homofóbica, como é a sociedade jamaicana, e, assim, sua afirmação pode ser lida como um elogio e um exemplo de transculturação e multiculturalismo.

O ambiente das discotecas permitia a experimentação de vários estilos de roupas: calções e bermudas de cetim com patins, ternos brancos, alta-costura, prêt-a-porter, muito lamê, lurex, lantejoula, enfim, muito brilho que agradava às travestis e às drag queens, as quais ainda eram fenômenos underground. Nesse período, pelo menos um cantor transformista de discoteca se destacou com sua excelente voz de falsete: Sylvester.

Por outro lado, explicar a predileção gay pela música disco apenas pela experimentação da moda é incorrer em reducionismo. Em primeiro lugar, a comunidade gay não era um bloco homogêneo e monolítico. Havia diversos estilos, desde as travestis e drag queens usando roupas femininas, passando para os efeminados e andróginos até o estilo hipermasculinizado ou butcher, cujo exemplo arquetípico é o grupo musical Village People.

Entretanto, pode-se afirmar que um estilo de vida hedonista se desenvolveu majoritariamente entre os homossexuais, representado pelo cruising (andar à deriva ou pegação). A prática do cruising assemelha-se a do flâneur, de Baudellaire (BENJAMIN, 1989), porém, mais do que perambular pelas ruas com ar blasé, o cruising era uma ver- 
dadeira "caça" de eventuais parceiros sexuais nos parques, saunas, bares e discotecas. Formaram-se verdadeiros guetos homossexuais como Greenwich Village e Christopher Street, em Nova York; Castro, em San Franscisco; South Beach, em Miami, etc. onde se podia praticar facilmente a pegação (cruising).

Para Nestor Perlongher (1987: 155-156), a paquera, ou deriva (cruising) é um modo característico dos sujeitos envolvidos nas transações homossexuais:

Trata-se de pessoas que saem à rua à procura de um contato sexual, ou simplesmente "vão para o Centro para ver se pinta algo", toda uma massa que se "nomadiza" e recupera um uso arcaico da rua. A rua, "microcosmos da modernidade" (Lefebre, 1978), torna-se algo mais do que mero lugar de trânsito direcionado ou de fascinação espetacular perante a proliferação consumista: é, também, um espaço de circulação desejante (a "errância sexual" de Maffesoli, 1985).

Ao analisar o soneto "A une passante", de Baudelaire (1985), Walter Benjamin mostra como o olhar do flâneur captura, singulariza o objeto furtivo de seu desejo, "aquilo que contrai o corpo em um espasmo - qual bizarro basbaque - não é a beatitude daquele que é invadido por Eros, em todos os recônditos do seu ser; é, antes, a perplexidade sexual que pode acometer um solitário" (1989: 118).

Para evitar o risco de criar uma identidade monolítica de promiscuidade para os homossexuais, estabelecendo uma imagem deteriorada (estigma) que poderia recobrir todo o self desses indivíduos (GOFFMAN, 1988), é necessário lembrar que o desejo de sexo sem compromisso afetivo é tradicionalmente encarado como tipicamente masculino, independentemente da orientação hetero ou homossexual (ALBERONI, s/d). Contudo, essa afirmação pode também incorrer em mais um estereótipo sobre a masculinidade. Segundo Perlongher, poder-se-ia esboçar uma analogia entre o flanar da boemia e a deriva das homossexualidades. "Explorar as possibilidades sensuais do fluxo das massas urbanas não é, por sinal, exclusivo de prostitutos e 'entendidos' (...) constitui uma versão particularizada de uma prática muito mais institucionalizada e conhecida o trottoir da prostituição feminina" (1987: 156).

Além disso, a dança representava a redescoberta do corpo - segundo Roberto Muggiati (1981: 109), "com a crise do petróleo, as pessoas passaram a valorizar coisas tão simples como andar, correr, se exercitar, dançar". Todavia, há que considerar também a influência dos estudos de Michel Foucault (1999) a respeito dos efeitos das disciplinas sobre os corpos, que foram divulgados nos meios acadêmicos e na mídia. Do mesmo modo o fisiculturismo deixava de ser também um esporte underground com a figura musculosa de Arnold Schwarzenegger entre outros.

Por fim, a imagem de uma diva sexualmente liberada pela revolução sexual era amplamente veiculada pela música disco. Nos anos 60, as cantoras de soul, em sua maioria, cantavam canções que falavam de mulheres que sofriam pelo abandono ou traição de seus amantes. Nas representações tradicionais das relações entre os sexos, segundo o sociólogo Francesco Alberoni, a mulher deseja continuidade do relacionamento; o homem, a descontinuidade. O homem a trai "não porque esteja interessado em outra mu- 
Iher, tampouco pelo gosto da conquista ou de aventura. Ele a trai para ser livre, para poder iludir sua vigilância, para sentir-se livre de sua possessividade amorosa, de seu controle" (s/d: 52).

Com a música disco, muitas das canções cantadas por mulheres ainda retratavam esse tema da traição e do abandono masculino, como por exemplo, "Don't leave me this way" (Thelma Houston, 1976) e "Young hearts run free" (Candi Staton, 1976). Todavia, clássicos como "I love the nightlife" (Alicia Bridges, 1978), "I will survive" (Gloria Gaynor, 1978) e "Shoot your best shot" (Linda Clifford, 1980), apresentavam mulheres seguras de si, donas de sexualidade liberada, quase sempre interpretados por cantoras negras. Era justamente essa imagem de deusa sexual, de femme fatale, de glamour que agradava aos gays, mas também incorria no mito da ninfomania da mulher negra.

No disco Portfolio, enquanto a canção "I need a man" se enquadra na temática da mulher lamentando o abandono de seu amado, "That's the trouble", de autoria de Grace Jones e Pierre Papadiamondis, apresenta uma mulher que só está interessada em

4 Saindo para dar um passeio à noite para ver/ as sombras do luar, quando esse cara/Começou a me seguir/e agora você entende/(Esse é o problema)/Então ele pegou minha mão, para minha surpresa,/Ele olhou seriamente nos meus olhos e disse/"eu gostaria que você viesse comigo para minha casa"//Esse é o problema)/Todo homem que eu vejo/Levando tudo a sério/Esse é problema se você quer, deixa estar/ Esse é o problema se você deseja ser livre/Ora, eu não percebi que ele era o/ Tipo do cara sério, e eu li sua carta,/ que diz "meu amor, você quer casar comigo?"/(Esse é o problema)/ Todo homem que eu vejo/Levando tudo a sério/Esse é problema se você quer, deixa estar/ Esse é o problema se você deseja ser livre. relações fugazes:

Stepping out to take a walk at night to see / The shadows of the moonlight, when this guy / Began to follow me and now you see. // (That's the trouble) // Then he took my hand, to my surprise, / He stared so seriously in my eyes and said / "Why, I'd glad for you to come on home with me." // (That's the trouble) // Every man I see, / Taking every little thing so heavily, / That's the trouble if you wanna, let you be, / That's the trouble if you really wanna be free. // Well I did not realize, he was the / Serious type of guy, when I read his letter, / which said "my love, will you marry me?" // (That's the trouble), / Every man I see / Taking every little thing so heavily, / That's the trouble if you wanna, let you be, / That's the trouble if you really wanna be free ${ }^{4}$.

A situação que a canção acima apresenta faz lembrar o ato da pegação, uma mulher flanando sozinha pela noite, encontra um homem que a convida para ir para casa dele e, depois receber uma carta com um pedido de casamento, ela lamenta que o problema resida no fato de que todos os homens levam as coisas a sério demais. $E$, se esse é o caso, deixa estar; mas ela quer ser livre. Há uma total subversão dos papéis tradicionalmente atribuídos aos gêneros: quase sempre é a mulher que se entrega por amor a um homem que depois a abandona.

Mas a recusa do eu lírico da canção também poderia significar a arte do coquetismo, ou seja, "fazer a quem ele se dirige sentir esse jogo instável entre o sim e o não, uma recusa de se dar, que poderia muito bem ser a esquiva que leva à entrega (...) Toda decisão definitiva põe fim à arte do coquetismo" (SIMMEL, 1993: 97). 
Por outro lado, a imagem de uma mulher sozinha flanando ou fazendo pegação em bares ainda hoje é pouco usual, não obstante o personagem de Diane Keaton no filme Looking for Mr. Goodbar (1977). Esse filme, inspirado no romance homônimo da escritora Judith Rossner (1975) e na trágica história verídica de Roseann Quinn (19441973), apresenta os perigos que essa prática pode trazer para as mulheres.

Muitos dos críticos consideram Grace Jones uma cantora de voz fraca e de pouca extensão, mas com muita expressividade, e atribuem a importância de sua obra mais às performances ao vivo do que necessariamente a seus discos, apesar de eles serem quase todos considerados clássicos. A maioria dos ensaios acadêmicos volta-se para as imagens e a persona pública que ela criou e, principalmente, para o apelo de suas performances.

Muito antes de Madonna criar sua dominatrix sádica, Dita, para a turnê The Girlie Show (1993) e o livro Sex (1992), Jones, inspirada talvez em Mae West, Betty Davis ${ }^{5}$ e The Velvet Underground, criava espetáculos em que ela apresentava homens musculosos e seminus no palco e dominação sádica. A revista Ebony descreve um desses concertos:

Grace Jones entra no palco usando um véu de noiva até o chão, um corselete negro, e meias arrastão presas por ligas luxuosas. Batendo um longo chicote de couro vermeIho, ela desfila de um lado para outro do pequeno palco, cantando seu sucesso I need a man, e inspecionando dois dançarinos masculinos seminus como se eles fossem tigres em sua jaula. O chicote estala e as calças largas dos dançarinos caem para revelar seus suportes de atletas ne-

5 Aqui se está referindo à modelo e cantora negra Betty Davis (1945- ), ex-mulher de Miles Davis, que escandalizava os anos 70 com uma postura liberada sexualmente no palco e nas letras de suas canções, e não à famosa atriz de cinema, Bette Davis (1908-1989). gros. Grace se afasta e inspeciona as mercadorias, ocasionalmente batendo nos traseiros despidos dos dançarinos com seu chicote. Ela não fica satisfeita. Ela dispensa os dançarinos e, da audiência que pula nos três lados do palco, agarra um homem pelo colarinho ('Vamos! Eu sei que você é gostoso!), puxa-o para o palco e ordena que ele tire a camisa. Logo, há dúzias de homens seminus no palco, e Grace está quase perdida num mar de corpos suados que giram. Um camarada tira toda a roupa (1979: 18).

A imagem da dominatrix sádica de Grace Jones, à primeira vista, pode parecer uma subversão dos papéis sexuais e raciais de maneira mais radical. Conseguindo interação com a plateia masculina que passou a participar ativamente do espetáculo, Jones não se contentou em ser a mulher masoquista, vítima do furor de seus senhores como as personagens femininas de Sade (1986) e/ou a personagem $O$ do livro de Pauline Reage (s/d). E, como num ato de vingança, ela manejou o chicote contra a carne branca dos dançarinos seminus numa tentativa simbólica de exigir reparação para os ancestrais escravizados (FANON, 1983: 186-188).

Na verdade, do ponto de vista psicanalítico, o sadismo e o masoquismo são os lados opostos de uma mesma moeda e o apego ao fetichismo é muito mais comum nos homens que nas mulheres. Para M'Uzan, "o masoquismo seria um sadismo voltado para o ego, tratando-o como gostaria de tratar o outro (...) sob a máscara da afirmação teatral de não ser nada, de fato domina o sádico, forçando-o a desempenhar o papel que ele, 
masoquista, parece ter. O poder do sádico é um simulacro; serve apenas como instrumento controlado" (apud SILVA FILHO, 1987: 43).

Portanto, a dominatrix de Jones é, antes de tudo, um simulacro repleto de ambiguidades. A canção "I need a man" é apenas um apelo desesperado de uma mulher

6 Para mais informações sobre a influência do fetiche e do sadismo na cultura popular contemporânea, cf. Valerie Steele, Fetiche: Moda, Sexo \& Poder, (trad. Alexandre Abranches Jordão). Rio de Janeiro: Rocco, 1997; e Janine Chasseguet-Smirgel, Ética e Estética da Perversão (trad. Vera Jacques). Porto Alegre: Artes Médicas, 1991.

7 Muitas histórias sobre o personagem Anansi foram recolhidas na Jamaica, entre 1920-21 por Martha Warren Beckwith e reunidas no livro Jamaica Anansi Stories. New York: The American Folk-Lore Society, 1924. Cf. também Velama Pollard, A Collection of Caribbean Folk Tales and Poems for Juniors. Kingston: Longman, 1985; Tololwa Mollel, Ananse's Feast: An Ashanti Tale. New York: Clarion Books, 1997; Charles Reasoner, Spider and His Son Find Wisdom: An Akan Tale. Vero Beach: Rourke Book Co. Inc., 1998; Louise Bennet, Anancy and Miss Lou. Kingston: Sangster's Bookstores Ltd, 1979; e James Berry, Spiderman Anancy. New York: Henry Holt and Company, 1998. abandonada pelo amante e desejando um homem que a trate bem: "I need a man, perhaps a man like you" (Eu preciso de um homem, talvez um homem como você), convida a canção. Mas o sadismo, a dominação, que num nível inconsciente é subserviência, bem como a androginia, são comportamentos ambivalentes. ${ }^{6}$

Nos dois álbuns seguintes, Fame (1978) e Muse (1979), Grace Jones e Tom Moulton seguiram basicamente a mesma fórmula de Portfolio (1977): o lado A com medleys, e o lado B com canções independentes entre si. Enquanto Fame produziu três sucessos "Do or die", "Fame" e "Autumn leaves"; o álbum Muse produziu apenas um, "On your knees". Nessa trilogia de música disco, os títulos dos álbuns sugerem um aspecto narcisista da cantora que cresce de "portfólio" para "fama" até se transformar em "musa". Porém, ela se revelou hábil em manipular sua imagem e aparência como o mito de Anansi.

Na história de opressão colonial dos povos afro-caribenhos, uma personagem mítica serviu como inspiração às estratégias de sobrevivência dos escravos e seus descendentes, constituindo-se como parte de seu imaginário e do habitus dessas populações. O nome dessa personagem ambígua é Anansi ou Anancy, o deus-aranha.

O mito de Anansi é extremamente popular no folclore jamaicano. Na Jamaica, as histórias sobre "Brer Anansi" são transmitidas oralmente às crianças pelos adultos em casa e, nas escolas pelos professores e pelos livros infantis. Originário da África Ocidental, o mito ainda hoje é encontrado em Gana, Costa do Marfim, Serra Leoa, Libéria, Togo, Daomé. ${ }^{7} O$ termo Anancy significa aranha, na língua dos Ashanti. Nas Américas, ele pode ser observado da Nova Escócia ao Brasil. Entretanto, é mais popular na Jamaica do que nos outros países americanos. De acordo com Pascale de Souza (1998: 7071), além da aparência de uma aranha cheia de truques, a indeterminação também caracteriza Anancy, que desafia categorizações. Ele é muitas vezes retratado como um ser humano com o dom de fiar, outras vezes como uma aranha com traços humanos, masculinos e/ ou femininos, a ambiguidade por excelência.

Comparativamente, pode-se dizer que Anancy possui semeIhanças com os personagens Pedro Malasartes e João Grilo, encontrados no Centro-Sul e no Nordeste brasileiros, respectivamente, por 
seus truques e artimanhas, ou, ainda, com o Pantagruel de François Rabelais (14941553), por sua glutonaria e insaciável apetite sexual (RABELO, 2006: 75).

Consciente da natureza flutuante da linguagem, Anancy engana outros personagens, em geral outros animais, por meio de mentiras ou recursos mais refinados. Os recursos retóricos de Anancy foram definidos por Louis Gates Jr. como poderes significadores, isto é, a maneira que os afro-americanos testam a habilidade das palavras de produzir sentidos convencionais, para introduzir um discurso de astúcias (1988: 45). Porém, Denis Forsythe, afirma que a arte de Anancy não se limita às distorções ou renovações dos significados das palavras e dos discursos, incluindo também o uso da linguagem corporal, como silvar ou chupar os dentes, ou fazer caretas, atitudes típicas encontradas nos jamaicanos (1983: 225).

Na canção "Do or die" (Fazer ou morrer), Grace Jones incorpora o deus-aranha ao cantar: "I've been called an operator/I can sell an eskimo snow/Baby you're a calculator/ But all you ever tell me is no/You make me run, run, run/I'll never give up/I've got to do or die" (Eu sou chamada de enganadora/Posso vender neve para esquimó/Meu bem, você é um calculista/Mas tudo que você me diz é não/Você me faz correr, correr, correr/Eu nunca desistirei/Ou eu faço ou eu morro). A dissimulação típica de Anansi faz parte dos jogos amorosos e eróticos, em que a mulher, tradicionalmente considerada hábil na arte de enganar, faz disso uma estratégia de sobrevivência e mistério para seduzir. Mas no estribilho da canção, Jones diz "I've got to do or die/I've got to make you mine/You'll never change my mind/cause I'm really in time/I've got to do or die" (Ou eu faço ou morro/Tenho que te possuir/você nunca vai mudar a minha cabeça/porque estou na hora certa/ ou eu faço ou morro). Essas são outras ambiguidades do eu lírico que chegou a uma situação-limite em que a simulação não é mais um expediente válido ou que funcione, mas sim a atitude tanto desesperada de tomada de decisão para sobreviver quanto calculada de domínio sobre o outro, o amante.

Para divulgar o álbum Fame, Jones fez apresentações na Europa, aparecendo em diversos programas de tevê, quase sempre usando uma mistura de maiô preto e minivestido frente única de lamê dourado, saltos altos e braceletes espiralados de metal dourado ou longas luvas de pele de leopardo. Sua performance memorável, porém, ocorreria nos EUA, na noite de Halloween, a partir da colaboração e da direção do artista gráfico e publicitário Jean-Paul Goude.

No início dos anos 70, Goude emigrou de Paris para Nova York a fim de trabalhar como diretor de arte na revista Esquire. Em 1974, ele publicou um artigo intitulado "América Dances", focalizando as diversas danças e subculturas dos brancos, negros, imigrantes latinos e gays. Por volta de 1977, Goude e Jones se encontraram e começaram um relacionamento amoroso e uma intensa colaboração artística. Goude relata assim sua reação quando viu Grace Jones em um espetáculo:

Eu fiquei assombrado quando pela primeira vez eu vi Grace Jones. Eu pude ver como o rapaz mediano que estava acostumado com garotas bonitas podia ficar assustado com sua aparência. Ela era tão poderosa (...) Eu tive a ideia de usar 
Grace Jones como o veículo ideal para meu trabalho. Ela tinha me inspirado. De um modo inesperado Grace chegou a me obcecar (GOUDE, 1981: 102).

Na noite de Halloween, no clube Roseland (Nova York), Jones e Goude criaram uma antológica performance que subvertia as apropriações colonialistas sobre a selva e os povos negros, deslocando as fronteiras de raça, sexo, sexualidade e gênero. O palco foi montado com andaimes e fumaça para recriar uma atmosfera industrial do Lower West Side. Por outro lado, havia também uma atmosfera de selva fornecida por tambores de percussionistas porto-riquenhos. Um ambiente híbrido composto pela selva mítica na selva urbana pós-moderna (GOUDE, 1981: 104).

No palco havia boxeadores lutando e pulando corda, usando protetores de cabeça e luvas, contrastando com a feminilidade das drag queens da plateia. Jones surgiu no palco vestindo um manto que foi retirado para revelar que ela estava usando um pequeno top que mal cobria seus seios, uma espécie suporte que os boxeadores usam para proteger a região genital e ataduras nas mãos. Ela cantava e simulava lutas, aplicando golpes e ganchos.

De acordo com Miriam Kershaw, a sequência inicial do espetáculo no Roseland envolve três importantes temas. Primeiro, um ritmo multicultural afro-latino foi introduzido pelos percussionistas porto-riquenhos estabelecendo uma ligação resistente com os ancestrais e as novas e criativas formas musicais dos afrodescendentes na América por meio da Diáspora africana. Segundo, o boxe refere-se a um lócus do orgulho afro-americano. A vigorosa performance de Jones como boxeadora remete a vários boxeadores afro-americanos famosos como Joe Louis. Terceiro, a performance ofereceu uma peça pós-moderna de construção de gênero como espetáculo. A apropriação da feminilidade pelas bichas da plateia ironicamente ressaltou a masculinidade dos boxeadores, enquanto Jones realizou uma apropriação do poder masculino pela subversão de gêneros. A performance no Roseland contribuiu para deslocar as fronteiras entre a arte e a vida. $\mathrm{O}$ esporte e o símbolo se fundiram no boxe como espetáculo. (KERSHAW, 1997: 20).

Para o clímax do espetáculo do Roseland, Jones e Goude ironizaram as apreensões colonialistas sobre a selva, a África, o homem e a mulher negros. Goude, em seu livro autobiográfico, Jungle Fever, descreve a cena final:

Imagine no meio de 6.000 fãs gritando, esse enorme animal é levado para o fim da passarela como no final de King Kong. Há perigo no ar - E se o tigre escapasse? Grace, vestida como um tigre, canta para a fera. Eles silvam e grunhem um para o outro. Ela abre a porta da jaula e, repentinamente, todas as luzes se apagam. A música para. A escuridão é completa! Então surge essa gravação de dois tigres urrando como se lutassem até a morte. Dez segundos assustadores se passam. Então as luzes e a música retornam, o tigre desapareceu e em seu lugar, Grace está cantando e mastigando um pedaço de carne. (GOUDE, 1981: 105).

Nos símbolos antigos, o tigre representa o poder destrutivo, ligado ao simbolismo da lua, ao mundo ctoniano e às regiões ocidentais ligadas à morte. Mas é também o símbolo da força, da coragem, do heroísmo, da destruição e da ferocidade. O tigre é símbo- 
lo de obscurecimento da consciência que representa nos sonhos um conjunto de impulsos instintivos recalcados, perigosos, prontos a inundar o consciente (JULIEN, 1993: 487488).

Segundo Paula Ben Amos (1980: 20), nas cortes de Benim, antes e durante a colonização europeia, as figuras do tigre e do leopardo estavam associadas à realeza, a um ritual de passagem que significava o triunfo da civilização sobre a natureza. Entretanto, com a colonização, a associação dos africanos com os grandes felinos passou a significar para os europeus que os africanos presumiam primitivismo e sensualidade selvagem (KERSHAW, 1997: 21).

Do mesmo modo que Grace Jones associou sua imagem ao leopardo, Josephine Baker meio século antes também esteve associada a esse grande felino. O produtor Henri Varna comprou para ela um leopardo de estimação chamado Chiquita, que se tornou a sensação dos círculos chiques de Paris. Baker era vista passeando pelas ruas parisienses com seu leopardo e também se apresentava com ele em seus concertos. Muitas vezes o leopardo escapava para o fosso da orquestra aterrorizando os músicos e trazendo maior excitação ao espetáculo. Baker também se apresentava como um felino no palco, com as mãos crispadas como as garras de um tigre, revelando sedutora ambiguidade. Sua postura orgulhosa pode ser lida como subversão da subordinação colonial; em seu próprio processo de se tornar domada e civilizada, Baker ganhou autoridade para domar o felino, assumindo o papel dominador. Ela chamou a atenção para as relações históricas de poder e das interações entre humano e animal, e, por extensão, homem e mulher e branco e negro (ZABEL, 2001: 315-316).

A performance de Grace Jones inspirava-se claramente na fi8 Andy Warhol's Intergura de Josephine Baker, conforme ela mesma admitiu em entrevista à revista Interview, de Andy Warhol, em $1985 .{ }^{8}$ Todavia, Jones dominou o tigre, mas terminou mastigando a carne; em vez de deview. October 1985, 58.21. Pieterse, White on Black, p. 178-182. monstrar o poder civilizador sobre o selvagem, ela se identificou com o reino animal (KERSHAW, 1997: 21). A ironia da performance se perdeu na fotografia usada para o convite do espetáculo no Roseland. Jean-Paul Goude apresentou uma imagem de Jones nua, de quatro, usando uma cauda, dentro de uma jaula, onde se lia "Não alimente o animal". Essa imagem massivamente reproduzida tende a reafirmar uma perspectiva colonial mais do que pós-colonial. Para alguns, essa imagem construída possui paralelos com a prática francesa e bárbara do final do século XIX de colocar seus sujeitos africanos e coloniais em jaulas nos jardins zoológicos perto das espécies não europeias de animais (idem, ibidem: 21).

Segundo Kershaw, a identificação de Grace Jones com Josephine Baker evoluiu por meio dessa performance para um pastiche nostálgico da exibição de primitivismo de Baker. Porém, Jones adicionou um nível de complexidade, oscilando entre explorar o mito "feminino" do "primitivo" e a construção "masculina" de selvageria ameaçadora. Essa instabilidade de gênero poderia ajudar a não essencializar o sujeito negro feminino. A questão crítica que se coloca é se tal material representa a aquisição de poder (empo- 
werment) ou não. Pode-se interpretar o uso que Jones faz desse material não como a repetição literal de associações degradantes, mas antes como um comentário irônico sobre essa iconografia de poder e subordinação (idem, ibidem: 21).

O ano de 1979 marcou o apogeu da música disco e também sua saturação na indústria cultural, desencadeando movimento contra ela com os seguintes slogans: "Disco sucks" (algo como música disco não presta) e "Death to disco" (Morte à disco). O auge da cruzada contra a música disco ocorreu em Chicago, no estádio Coniskey Park, na noite de 12 de julho, quando milhares de discos desse gênero foram queimados, o que resultou na depredação do estádio. Essa noite ficou conhecida como Noite da Demolição da Música Disco. Segundo Behrens (2004), "alguns críticos argumentam que na reação contra a música disco estavam implícitos machismo e preconceito, um ataque sobre uma estética cultural que era não branca e não necessariamente heterossexual".

Essa saturação e reação levaram a quedas vertiginosas nas vendagens de discos de músicos e cantores ligados à discothèque. Talvez seja por esse motivo que o disco Muse de Grace Jones apresentou baixa vendagem em comparação aos dois anteriores, e permanece até hoje como seu único álbum que não foi lançado no formato CD. Assim, dois meses após a noite da demolição da música disco, as paradas de sucesso voltaram a ser dominadas pelo rock, pop e country. A televisão também passou a ignorar os músicos e cantores associados à música disco. Dois anos depois, muitas gravadoras que eram consideradas celeiros daquele gênero musical faliram ou foram compradas por outras companhias, das quais podemos citar TK Records, Casablanca Records, RSO Records, etc.

Contudo, naquele período, a colaboração de Jones e Goude se havia intensificado, e, tal como o deus-aranha Anancy, eles reinventaram a imagem de Jones para que ela pudesse continuar sobrevivendo na mídia. Ela adotou um corte de cabelo que se tornaria um ícone dos anos 80, o flap top (topo achatado), isto é, o corte utilizado pelos soldados, com as laterais raspadas e o topo mais alto. Esse corte acentuou ainda mais sua imagem andrógina. Os maiôs e corseletes deram lugar aos ternos amplos de Giorgio Armani e aos cortes perfeitos de Issei Myiaki, que ditaram a moda no início dos anos 80 .

Quanto à música, em 1980, Jones abandonou a disco, passando a produzir outra trilogia de uma versão chique de reggae e new wave que a colocou entre os melhores cantores do início daquela década que se iniciava. Suas performances continuaram a questionar a iconografia associada às representações tradicionais e "essencializadas" de masculino/feminino, de branco/negro e de civilizado/bárbaro.

A obra de Grace Jones, portanto, remete à ressignificação dos estereótipos coloniais sobre a mulher negra. Além das ambiguidades e transposição de fronteiras culturais, étnicas e de gênero que essa obra propõe, ela também se insere na cultura do simulacro das sociedades de massa. Os sentidos e significados são repensados a partir da transculturação, da perda de visões e identidades essencialistas e monolíticas, e também dos enfrentamentos, negociações, circularidade e hibridismo culturais. Desse modo, essas ambiguidades são produtos e produtoras de certa perplexidade frente às múltiplas 
identidades e papéis dos sujeitos sociais ao nos interrogar sobre quem realmente somos e o que queremos.

\section{REFERÊNCIAS BIBLIOGRÁFICAS}

ALBERONI, Francesco. O erotismo: fantasias e realidades do amor e da sedução. Trad. Élia Edel. São Paulo: Círculo do Livro, s/d.

AMOS, Paula Ben. The Art of Benin. London: Thames and Hudson, 1980.

ANDERSON, Carolyn G. "En route to transnational postmodernism: Grace Jones, Josephine Baker and the African diaspora". In: Social Science Information. Thousand Oaks/Paris: Sage Publications/The Foundation Maison des Sciences de I'Homme, vol. 32, n. 3, sept. 1993: 491-512.

BAUDELAIRE, Charles. As Flores do Mal. Trad. Ivan Junqueira. Rio de Janeiro: Nova Fronteira, 1985 (edição bilíngue)

BECKWITH, Martha W. Jamaica Anansi Stories. New York: The American Folk-Lore Society, 1924.

BEHRENS, Andy. Disco demolition: Bell-bottoms be gone! (11/08/2004). In: http://sports. espn.go.com/espn/page3/story?page=behreus/040809. Acesso em 17/05/10.

BENJAMIN, Walter. Charles Baudelaire um lírico no auge do capitalismo. Trad. José Martins Barbosa, Hemerson Alves Baptista. 1. ed. São Paulo: Brasiliense, 1989 (Obras Escolhidas, v. 3)

BENNET, Louise. Anancy and Miss Lou. Kingston: Sangster's Bookstores Ltd, 1979.

BERRY, James. Spiderman Anancy. New York: Henry Holt and Company, 1998.

BIVAR, Antônio. O que é punk. 3. ed. São Paulo: Brasiliense, 1984.

CABRERA, Olga. "Las culturas de migración en las fronteras caribeñas: Caribe Insular y Brasil Caribe". In: CORTÉS ZAVALA, Maria Teresa et al. (org.). Región, Frontera y Prácticas Culturales en la Historia de América Latina y el Caribe. Morelia/Goiânia: Universidad Michoacana de San Nicolás de Hidalgo/UFG-Cecab, 2002: 149-166.

CHACON, Paulo. O que é rock. São Paulo: Brasiliense, 1982.

CHASSEguet-SMIRGEL, Janine. Ética e Estética da Perversão. Trad. Vera Jacques. Porto Alegre: Artes Médicas, 1991.

DAUFOUY, Phillipe; SARTON, Jean-Pierre. Pop Music/Rock. Trad. Carlos Lemos. 2.ed. Lisboa: A Regra do Jogo Edições, 1981.

DAWIDJAN, Wresch. "Grace Jones prays" (1978). In:

http://dancemusic.about.com/od/discoflashback/a/GraceJones.htm, Acesso em 01/07/08.

DELEUZE, Gilles; GUATTARI, Félix. Rhizome. Paris: Minuit, 1976.

DISCO MUSEUM. “Grace Jones' Biography”. In: http://www.discomuseum.com/GraceJones.html, Acesso 01/07/08.

EBONY. Chicago, July 1979.

FANON, Frantz. Pele negra, máscaras brancas. Trad. Adriano Caldas. Rio de Janeiro: Fator, 1983.

FORSYTHE, Denis. Rastafari: for the healing of the nation. Kingston: Zaika, 1983.

FOUCAULT, Michel. Vigiar e punir: nascimento da prisão. Trad. Raquel Ramalhete. 21. ed. Petrópolis: Vozes, 1999. 
GATES, Jr., Henry Louis. The Signifying Monkey. New York: Oxford University Press, 1988.

GLISSANT, Édouard. Poetics of Relation. Trad. Betsy Wing. Ann Arbor: The University of Michigan Press, 2000.

GOFFMAN, Erving. Estigma: Notas sobre a Manipulação da Identidade Deteriorada. Trad. Márcia Bandeira de Mello Leite Nunes. 4. ed. Rio de Janeiro: Guanabara Koogan, 1988.

GOLDMAN, Albert. Disco. New York: Hawthorn Books, 1978.

GOUDE, Jean-Paul. “America Dances”. In: Esquire. New York, December, 1974, p. 72-75. . Jungle Fever. New York: Xavier Moreau Inc., 1981.

HALL, Sutart. Da Diáspora: Identidades e Mediações Culturais. Org. Liv Sovik. Trad. Adelaine La Guardia Resende et al. Belo Horizonte/Brasília: Ed. UFMG/Unesco, 2003.

HITE, Shere. O Relatório Hite: Um estudo profundo sobre a sexualidade feminina. Trad. Ana Cristina César. 16. ed. São Paulo: Difel, 1983.

JACOBI, Jolande. "Símbolos de uma análise individual". In: JUNG, Carl G. (org). O Homem e seus símbolos. Trad. Maria Lúcia Pinho. 15. ed. Rio de Janeiro: Nova Fronteira, 1997: 272-303.

JULIEN, Nadia. Dicionário dos Símbolos. Trad. Luiz Roberto Malta; Margareth Fiorini. São Paulo: Rideel, 1993.

JULES-ROSETTE, Benetta. Josephine Baker in Art and Life: The icon and the image. Champaing: University of Illinois Press, 2007.

KERSHAW, Mirian "Post-Colonialism and Androgyny: The performance art of Grace Jones". In: Art Journal, v. 56, n. 4 (Winter). New York: College Art Association, 1997: 19-25.

LEFEBVRE, Henri. "Introdución a la psicosociologia de la vida cotidiana". In: De lo rural a lo urbano. Barcelona: Península, 1978.

LERNER, Gerda (ed.). Black Women in White America: A Documentary History. New York: Randon House, 1973.

MADEMOISELLE. New York, November, 1982.

MADONNA. Sex. New York: Warner Books, 1992.

MAFFESOLI, Michel. A sombra de Dionísio: contribuição a uma sociologia da orgia. Trad. A. R. Trinta. Rio de Janeiro: Graal, 1985.

MILLS, David. "Blaxploitation 101: A Brief Film History Of Sticking It To The Man" In: The Washington Post, Nov. $4^{\text {th }}, 1990$, at G.1, Col. 2.

MOLLEL, Tololwa. Ananse's Feast: An Ashanti Tale. New York: Clarion Books, 1997.

MUGGIATI, Roberto. Rock, o grito e o mito: a música pop como forma de comunicação e contracultura. 3a ed. Petrópolis: Vozes, 1981.

PERLONGHER, Nestor. O negócio do michê: prostituição viril em São Paulo. São Paulo: Brasiliense, 1987.

POLLARD, Velma. A Collection of Caribbean Folk Tales, Legends and Poems for Juniors. Kingston: Longman, 1985.

RABELO, Danilo. "Off the coast of me: representaciones sobre el inmigrante caribeño en Estados Unidos". In: Archipiélago. México: Confluencia S.A. de C.V. y Archipiélago A.C., 2003, n. 41, jul.-sept.: 36-42.

. Rastafari: Religiosidade e Hibridismo Cultural na Jamaica, 1930-1981. Brasília: UnB, 2006. Tese (Doutorado em História). 
REAGE, Pauline. A história de O. Trad. Maria de Lourdes N. Pinto. São Paulo: Círculo do Livro, s/d.

REASONER, Charles. Spider and His Son Find Wisdom: An Akan Tale. Vero Beach: Rourke Book Co. Inc., 1998.

ROSSNER, Judith. Looking for Mr. Goodbar. New York: Simon \& Schuster, 1975.

SADE, Marquês de. Ciranda dos Libertinos. Org. e trad. L.A. Contador-Borges. São Paulo: Max Limonad, 1986.

SHAKESPEARE, William. A Tempestade. Trad. Beatriz Viégas-Faria. Porto Alegre: L\&PM, 2006.

SILVA FILHO, Antônio Carlos Pacheco e. Perversões Sexuais: um estudo psicanalítico. São Paulo: EPU, 1987.

SIMMEL, Georg. Filosofia do Amor. Trad. Luís Eduardo de Lima Brandão. São Paulo: Martins Fontes, 1993.

SOUZA, Pascale de. "The Signifying Spider". In Revista Mexicana del Caribe. Chetuamal, Quintana Roo: Ciesas/Ecosur/Instituto Mora/UQRoo, 1998, Año III, n. 6: 68-99.

STEELE, Valerie. Fetiche: Moda, Sexo \& Poder. Trad. Alexandre Abranches Jordão. Rio de Janeiro: Rocco, 1997.

ZABEL, Barbara. "The Expatriates of the Machine-Age: Josephine Bake and Alexander Calder in Paris". In: CHEW III, William L. (ed.) National Stereotypes in Perspective: Americans in France, Frenchmen in America. Amsterdam: Rodopi, 2001, (Studia Imagologica: Amsterdam Studies on Cultural Identity, 9): 299-326.

Danilo Rabelo é professor adjunto de sociologia do Centro de Ensino e Pesquisa Aplicada à Educação - Cepae e do Programa de Pós-Graduação em História da Universidade Federal de Goiás, e doutor em história pela UnB (2006). 
